\title{
Comparison of Alcohol and Fatty Acid Adsorption on Hydrogenated DLC Coatings Studied by AFM and Tribological Tests
}

\author{
Rok Simič - Mitjan Kalin* \\ University of Ljubljana, Faculty of Mechanical Engineering, Slovenia
}

\begin{abstract}
Adsorption on hydrogenated diamond-like carbon (DLC) coatings with respect to boundary lubrication has been studied only very rarely, even though such adsorption has proved to be one of the main boundary-lubricating mechanisms for metal contacts. For this reason, we used atomic force microscopy (AFM) and tribotests to study the ability of hexadecanol and hexadecanoic acid to adsorb onto DLC and affect the tribological properties of DLC coatings, where steel was used as a reference. We have shown that alcohols and fatty acids can adsorb onto the DLC under static conditions. However, under dynamic tribocontact conditions, although alcohol and fatty acid molecules help to decrease the wear of the coatings, they are inefficient in reducing the friction. In all the experiments the fatty acid proved to have superior adsorption abilities compared to the corresponding alcohol. Based on our results and the existing literature, tentative adsorption mechanisms that include an environmental species effect, a temperature effect and a tribochemical effect are discussed for DLC surfaces.
\end{abstract}

Keywords: DLC, AFM, fatty acid, alcohol, adsorption, tribology

\section{INTRODUCTION}

Low-friction, low-wear and anti-adhesion properties are characteristics of diamond-like carbon (DLC) coatings, making them very useful for the protection of the contact surfaces of mechanical systems, see [1] to [3]. Since the contact surfaces of various mechanical systems are usually lubricated, an investigation of the effects of lubricants and additives on DLC coatings is crucial for the improvement and adaptation of the lubrication for DLC coatings. It is known that DLC coatings are, in general, chemically very stable and inert towards external species under static conditions [4]. On the other hand, under dynamic tribocontact conditions DLC surfaces can interact with opposing surfaces and with the gaseous molecules present in their surroundings [4]. Hydrogen, either atmospheric or originating from the coating itself, can passivate the surface's dangling bonds and cause H-termination, which results in very low friction [5] to [7]. It was shown that in the case of water lubrication DLC can also tribochemically react with water molecules, where besides hydrogen passivation, $\mathrm{OH}$ groups are also formed on the DLC surface, causing $\mathrm{OH}-$ termination [8]. Although H-termination seems to be preferable to $\mathrm{OH}$-termination due to the absence of van der Waals forces between the opposing surfaces, the $\mathrm{OH}$-termination is assumed to play a significant role in reducing the friction and wear of the DLC contacts by preventing the strong adhesive bonds between the non-passivated surfaces in the contact [4].

The formation of an OH-terminated carbon surface was also reported by other authors [9], who used GMO as an additive on the ta-C surfaces. Hydroxyl groups from the GMO were assumed to tribochemically react with the friction-activated ta-C surfaces causing ultra-low friction. The hydroxylation of the surfaces was also suggested in another study where glycerol was used as an additive [10]. Here, the authors proposed that hydroxylated surfaces also enhance the intercalation and adsorption of the surrounding alcohol molecules via hydrogen bonding.

The tribochemical reactions of DLC surfaces were also confirmed with relatively complex boundarylubricating additives, like ZDDP and MoDTC [11] to [13]. It was suggested that additive species interact with the dangling bonds of the friction-activated carbon surfaces, forming low-shear $\mathrm{MoS}_{2}$ sheets on the surface.

Nevertheless, the base oils also affect the performance of the DLC coatings [14] to [17]. Increasing the oil's viscosity was found to decrease the wear of the DLC contacts in boundary-lubricating conditions, although the friction increased [15] and [16]. An improved wear performance due to the polarbased adsorption was also reported as the degree of unsaturation and the polarity of the base oil was increased [17].

Although the understanding of the lubrication of DLC coatings has improved drastically in the past decade, a systematic investigation of the adsorption of some polar groups like hydroxyl and carboxyl is still necessary. Since the chemisorption of polar molecules proved to be one of the efficient boundary-lubrication mechanisms for steel surfaces, it is very relevant to study the effect of such molecules on DLC coatings. 
In this work we have focused on the adsorption ability of alcohols and fatty acids on DLC because these molecules have proved to be efficient in improving the tribological properties of steel contacts. To examine the adsorption ability on the nanoscale and in the absence of any mechanical and tribological effects the experiments were performed under controlled, static conditions using an atomic force microscope (AFM). The DLC and steel surfaces were exposed to various concentrations of hexadecanol and hexadecanoic acid in hexadecane, and the surface coverage of the adsorbed polar molecules was measured using the AFM. Tribological tests using boundary-lubricated conditions were also performed to correlate the wear and friction behaviors with the AFM results.

\section{EXPERIMENTAL}

\subsection{Materials}

Steel (AISI 52100/DIN 100Cr6) discs of 24-mm diameter were used in this study. The hardness of the discs was $850 \mathrm{HV}$, as measured with a microhardness tester (Leitz Miniload, Wild Leitz GmbH, Germany). The discs were polished to an average surface roughness of $R_{a}=3$ to $4 \mathrm{~nm}$ for the AFM analyses and $R_{a}=30$ to $40 \mathrm{~nm}$ for the tribological tests, as measured using a CP-II AFM (Veeco, USA). A very low surface roughness in the case of the AFM analyses was necessary in order to observe the adsorbed species on the surface. Standard 100Cr6 steel bearing balls with a surface roughness $R_{a}$ of 10 to $15 \mathrm{~nm}$ were used as a counter body in the ball-on-disc tribological tests.

Half of the steel discs and balls were coated with $1.5 \mu \mathrm{m}$ of hydrogenated amorphous diamondlike carbon (a-C:H, 30\% H). Two interlayers - a Ti interlayer and a hydrogenated amorphous diamondlike carbon layer containing $\mathrm{Si}$ and $\mathrm{O}(\mathrm{a}-\mathrm{C}: \mathrm{H}: \mathrm{Si}: \mathrm{O})$ - were deposited between the coating and the steel substrate for better adhesion of the coating. All the layers were deposited using a hybrid PVD/PACVD process (Sulzer Sorevi SAS, Limoges, France). The DLC sample composition is presented in Fig. 1. The coating deposition only had a minor effect on the surface roughness. The surface roughness $R_{a}$ of the steel and the DLC-coated samples is presented in Table 1.

The polar molecules selected for the adsorption analyses in this work were straight-chain hydrocarbons with 16 carbon atoms and a hydroxyl $(\mathrm{OH})$ or carboxyl (COOH) end-group, i.e., hexadecanol and hexadecanoic acid (Merck KGaA, Darmstadt,

Germany). For the AFM analyses the hexadecanol and hexadecanoic acid molecules were introduced into the hexadecane (Merck KGaA, Darmstadt, Germany) in various concentrations from 2 to $20 \mathrm{mmol} / \mathrm{l}$.

For the tribological tests the polar molecules were mixed into a polyalphaolephin PAO6 base oil (Neste Oil, Espoo, Finland) with a kinematic viscosity of $30 \mathrm{~mm}^{2} / \mathrm{s}$ at $40^{\circ} \mathrm{C}$, again with concentrations from 2 to $20 \mathrm{mmol} / \mathrm{l}$. It was assumed that the adsorption from the PAO and hexadecane is relatively similar, despite the solvents having different structures [18]. Tribotests with pure PAO6 oil were also made to serve as a reference.

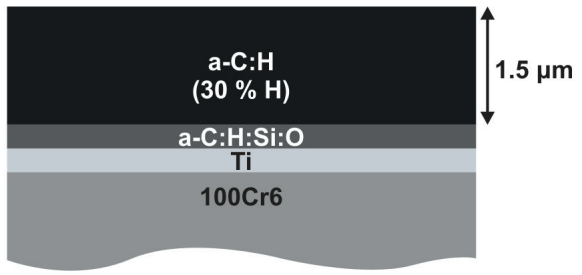

Fig. 1. Schematic cross-section of the DLC-coated 100Cr6 steel samples

Table 1. Surface roughness $R_{a}$ of the steel and DLC-coated samples; only the discs were used for the AFM adsorption analysis

\begin{tabular}{lcccc}
\hline & Steel disc & DLC disc & Steel ball & DLC ball \\
\hline AFM & $3 \pm 0.4 \mathrm{~nm}$ & $4 \pm 0.2 \mathrm{~nm}$ & $/$ & / \\
Analysis & $3 \pm 0.2 \mathrm{~nm}$ & $15 \pm 0.3 \mathrm{~nm}$ \\
\hline Tribotests & $30 \pm 5 \mathrm{~nm}$ & $40 \pm 5 \mathrm{~nm}$ & $10 \pm 0.2 \mathrm{~nm}$ \\
\hline
\end{tabular}

a)

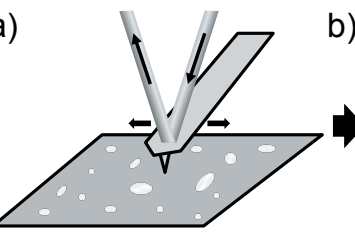

Fig. 2. Schematic representation of a) the AFM; and b) an image of the surface, where the adsorbed molecules appear in the shape of small bright spots; the A denotes the whole scanned area, while $A_{i}$ is the projected surface area of a single spot

\subsection{AFM Analysis}

Prior to the tests, the samples were cleaned by sonication in ethanol for $1 \mathrm{~min}$ and then left to dry in air. The analysis of the samples prior to their exposure to the solutions revealed no polishing or cleaning residues on the surfaces. Moreover, analyses of the DLC were performed after the coating deposition, where no polishing residues could be present due to industrially defined cleaning and subsequent coating deposition. Moreover, after exposing the samples 
to pure hexadecane (without alcohol or fatty acid molecules) and subsequent cleaning the AFM data revealed no surface debris or aggregates.

For the final analysis equally sized drops of mixtures were spread over the surfaces. Then, one set of samples was left at $25{ }^{\circ} \mathrm{C}$ for 10 minutes and the other at $80{ }^{\circ} \mathrm{C}$ for 20 minutes to allow the adsorption of the hexadecanoic acid molecules onto the surfaces. Afterwards, the samples were cleaned by sonication in ethanol for one minute to remove the unbound molecules, and then left to dry in air. Samples were then analyzed using the AFM in contact mode at a constant load, which proved to be a suitable technique for the imaging of adsorbed layers in our previous research. About 10 to 20 scans of $50 \mu \mathrm{m} \times 50 \mu \mathrm{m}$ were collected from various locations on a single sample to ensure statistically representative results. The analyses were made using the ProScan 1.8 Data Acquisition image-analyzing software associated with the AFM. The topographic images were used to determine the average surface coverage with the remaining adsorbed molecules, which appeared in groups in the shape of small islands that were scattered across the surface, Fig. 2. The surface coverage $(S C)$ was calculated as follows:

$$
S C=\frac{\sum_{i=1}^{N} A_{i}}{A},
$$

where $N$ is the number of adsorption spots, $A$ is the whole scanned area, and $A_{i}$ is the projected surface area of one adsorption spot, Fig. 2.

\subsection{Tribological Tests}

The tribological tests were performed using a CETR UMT tribometer (CETR, CA, USA) with a ballon-flat reciprocating test geometry. Self-mated contacts were always used. In this way the chemical reactions between the DLC and the additives could be observed, without the interference from the steel counter body, which affects the reaction products and befogs the actual reactivity of the DLC. The tests were performed at $25{ }^{\circ} \mathrm{C}$ and at $80{ }^{\circ} \mathrm{C}$. The normal load was set to $10 \mathrm{~N}$, corresponding to $1 \mathrm{GPa}$ of maximum initial Hertzian contact pressure. The tests with a $6.8-\mathrm{mm}$ stroke consisted of 7350 cycles to reach a total sliding distance of $100 \mathrm{~m}$. The average relative contact velocity was set to $0.01 \mathrm{~m} / \mathrm{s}$, so the boundary-lubricating conditions were ensured. The characteristic coefficient of friction (COF) for a specific test was determined as the average coefficient of friction over the last 3000 cycles. Each experiment was repeated several times to ensure statistically relevant results. An optical microscope equipped with a CCD camera (DS-fi1, Nikon Corp., Tokyo, Japan) was used to verify that the coating did not wear through and to measure the diameters of the wear scars on the balls. The wear volume was subsequently calculated. The wear volume on the discs, however, was usually below the limits of the technique used and was not measured.

\section{RESULTS}

\subsection{AFM}

Examples of the topographic images of the surfaces after their exposure to the solutions of alcohol or fatty acid in the PAO and cleaning are shown in Fig. 3. The surfaces were partially covered with islands of adsorbed molecules of the alcohol or fatty acid that were retained on the surfaces after the ultrasonic cleaning. Dispersive intermolecular forces caused the molecules to merge into groups and appear in the images as nanoscopic bright spots. The total areal size of these spots was found to depend on the concentration, temperature, type of additive and type of surface. This is discussed in detail later on. On the other hand, for the height of the spots, which was typically from 10 to $25 \mathrm{~nm}$, no such obvious correlations to the parameters studied in this work were found. Therefore, the height of the spots was assumed to depend primarily on the cohesive intermolecular forces between the molecules in the mixtures rather than on their interactions with the substrates.

The measured surface coverage with adsorbed molecules as a function of their concentration at 25 ${ }^{\circ} \mathrm{C}$ is presented in the graph in the Fig. 4a. The surface coverage was increasing monotonously with the increasing concentrations for both additives and on both surfaces. It is clear that the surface coverage of the steel with alcohol molecules $(\mathrm{Steel}+\mathrm{OH})$ was the lowest across the whole range of tested concentrations. The measured surface coverage was $0.24 \%$ at $2 \mathrm{mmol} / \mathrm{l}$ and was increasing monotonously up to $0.64 \%$ at $20 \mathrm{mmol} / \mathrm{l}$. Considering the assumed nonreactivity of the DLC, it was surprising to measure a higher surface coverage of alcohol molecules on the DLC surface (DLC+OH) compared to the steel. The surface coverage on the DLC was $0.47 \%$ at $2 \mathrm{mmol} / 1$ and was increasing up to $0.92 \%$ at $20 \mathrm{mmol} / \mathrm{l}$ for the alcohol molecules. As expected, due to the higher polarity of the fatty acid molecule compared to the corresponding alcohol molecule, we measured a higher surface coverage when the fatty acid was used 


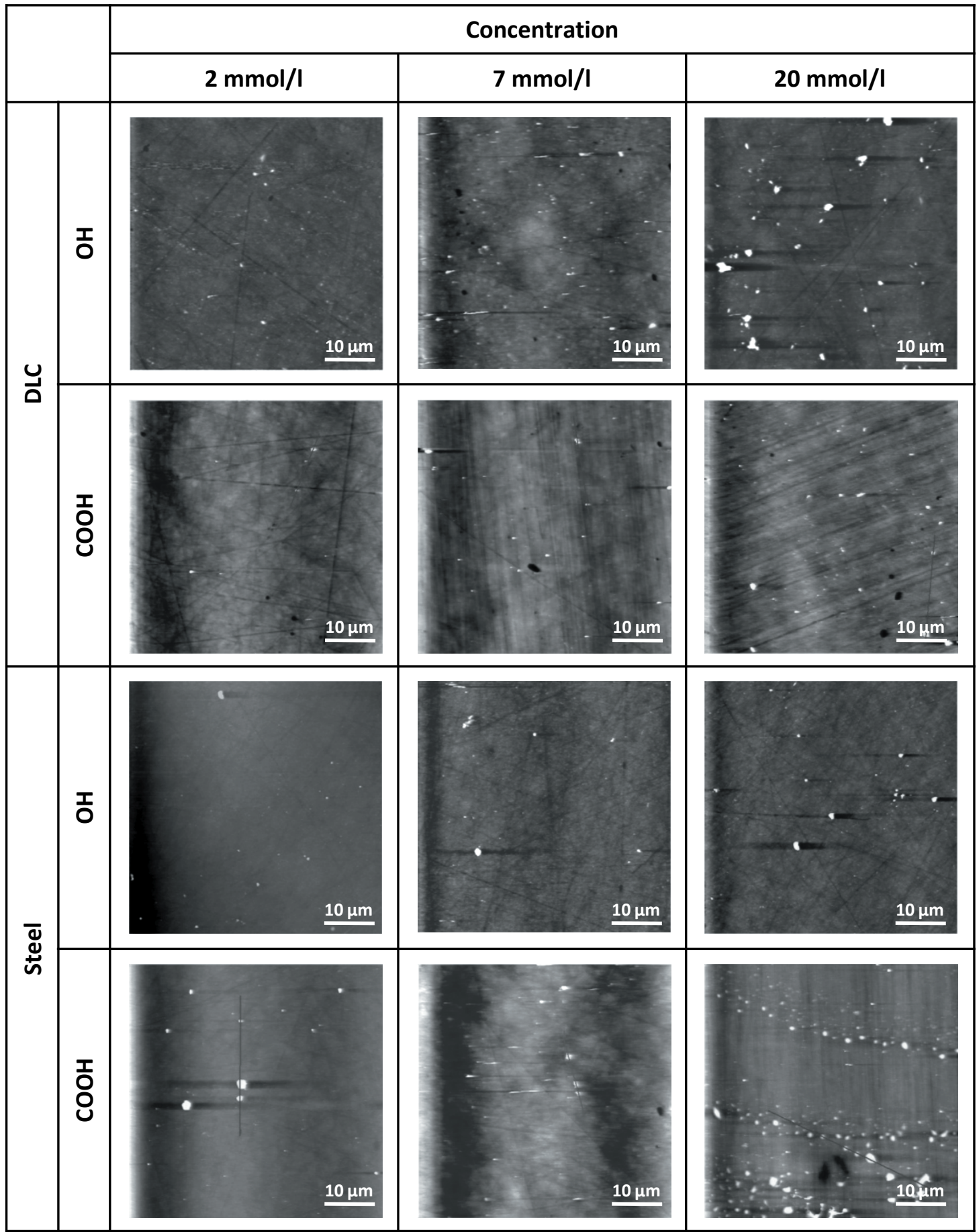

Fig. 3. AFM topographic images of the DLC and steel surfaces after their exposure to various solutions of alcohol (OH) or fatty acid (COOH) and cleaning

instead of the alcohol. This was true for the DLC and for the steel surface. Again, the surface coverage was increasing monotonously with increasing concentration for both surfaces. In contrast to the adsorption of the alcohol, the surface coverage with fatty acid molecules was mostly higher on the steel $(\mathrm{Steel}+\mathrm{COOH})$ than on the DLC $(\mathrm{DLC}+\mathrm{COOH})$. And although the surface coverage at lower concentrations of the fatty acid was relatively similar for the steel and DLC, the surface coverage for the steel was increasing 

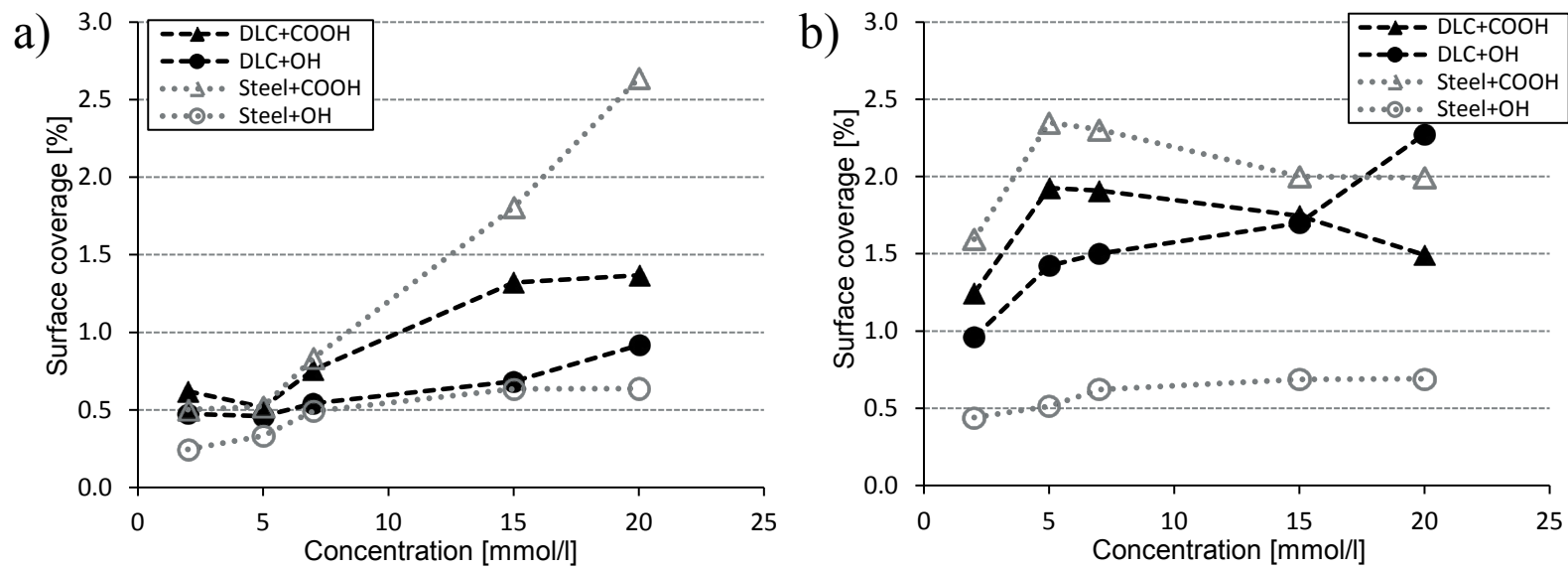

Fig. 4. Surface coverage with adsorbed alcohol $(\mathrm{OH})$ or fatty acid $(\mathrm{COOH})$ molecules for $\mathrm{DLC}$ and steel surfaces at a) $25^{\circ} \mathrm{C}$ and b) $80{ }^{\circ} \mathrm{C}$ as measured with the AFM

with a significantly higher rate than for the DLC. At $20 \mathrm{mmol} / \mathrm{l}$ the surface coverage with fatty acid molecules was $1.37 \%$ on the DLC and $2.64 \%$ on the steel surface.

When the temperature was set to $80{ }^{\circ} \mathrm{C}$ the surface coverage increased a great deal at low concentrations for both additives and on both surfaces, Fig. $4 \mathrm{~b}$, compared to the corresponding coverage at $25^{\circ} \mathrm{C}$, Fig. $4 \mathrm{a}$. At $80^{\circ} \mathrm{C}$, the surface coverage with alcohol molecules on the steel surface $($ Steel $+\mathrm{OH})$ was $0.44 \%$ at $2 \mathrm{mmol} / 1$ and $0.69 \%$ at $20 \mathrm{mmol} / \mathrm{l}$. The alcohol molecules again adsorbed better on the DLC than on the steel. The surface coverage with alcohol molecules on the DLC (DLC+OH) was $0.96 \%$ at 2 $\mathrm{mmol} / \mathrm{l}$ and a surprisingly high $2.28 \%$ at $20 \mathrm{mmol}$. The fatty acid molecules tended to absorb better on the DLC $(\mathrm{DLC}+\mathrm{COOH})$ than the alcohol molecules, similar to the situation at $25^{\circ} \mathrm{C}$. At $80{ }^{\circ} \mathrm{C}$ the surface coverage with fatty acid molecules on the DLC was
$1.25 \%$ at $2 \mathrm{mmol} / 1$, then it increased a lot to $1.93 \%$ at $5 \mathrm{mmol} / \mathrm{l}$, and above $5 \mathrm{mmol} / \mathrm{l}$ it was decreasing slowly to a value of $1.49 \%$ at $20 \mathrm{mmol} / \mathrm{l}$. As for the steel, the surface coverage with fatty acid at $80{ }^{\circ} \mathrm{C}$ was $1.59 \%$ at $2 \mathrm{mmol} / \mathrm{l}$, then it increased greatly to $2.35 \%$ at $5 \mathrm{mmol} / \mathrm{l}$, and above $5 \mathrm{mmol} / \mathrm{l}$ it was decreasing gradually to a value of $1.99 \%$ at $20 \mathrm{mmol} / \mathrm{l}$. Therefore, the adsorption of fatty acid on steel $(\mathrm{Steel}+\mathrm{COOH})$ showed similar behavior as on the DLC; however, higher values of the surface coverage were measured on the steel than on the DLC. This is a similar relation to the one that was observed at $25^{\circ} \mathrm{C}$, Fig. 4 a.

\subsection{Tribotests}

The coefficients of friction (COFs) and ball-wear volumes that were measured for each additive concentration are presented in Figs. 5 and 6. Fig. 5a shows the coefficient of friction for a steel contact a)

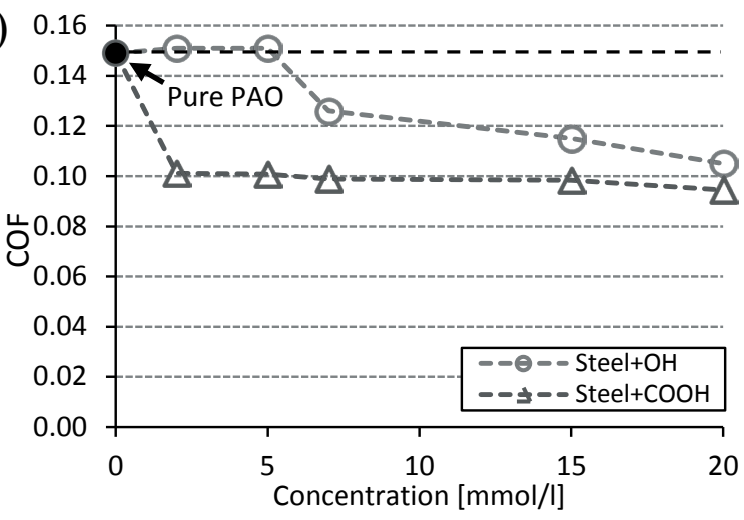

b)

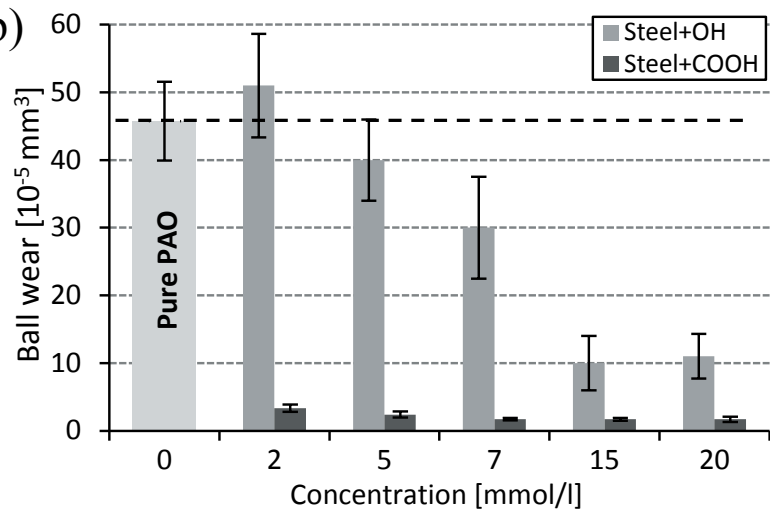

Fig. 5. a) Coefficient of friction (COF) and b) ball wear for the steel contact lubricated by PAO oil with added different concentrations of hexadecanol $(\mathrm{OH})$ or hexadecanoic acid $(\mathrm{COOH})$ 

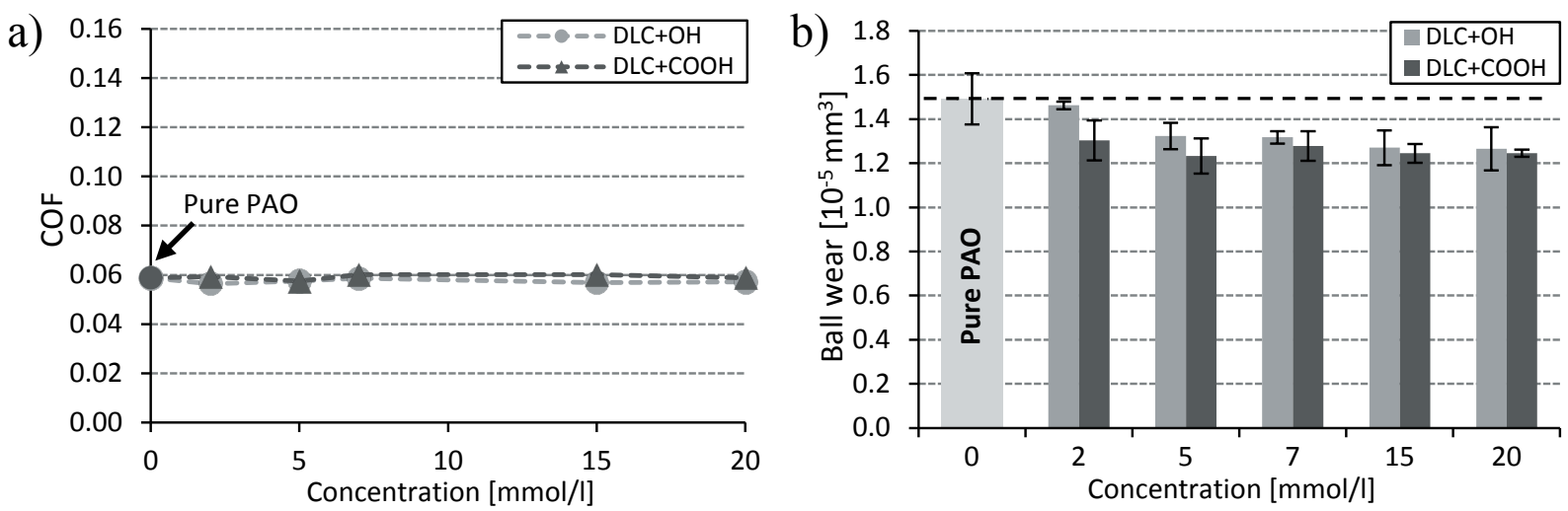

Fig. 6. a) Coefficient of friction (COF) and b) ball wear for the DLC contact lubricated by PAO oil with added different concentrations of hexadecanol $(\mathrm{OH})$ or hexadecanoic acid $(\mathrm{COOH})$

lubricated with various concentrations of alcohol or fatty acid in the PAO base oil. The coefficient of friction with just the base oil being used (Fig. 5a) was approximately 0.15 . When alcohol was added, the coefficient of friction did not change for additive concentrations up to $5 \mathrm{mmol} / \mathrm{l}$. At $7 \mathrm{mmol} / \mathrm{l}$ the coefficient of friction decreased to a value of 0.13 , and was gradually decreasing with an increasing alcohol concentration. At $20 \mathrm{mmol} / \mathrm{l}$ the coefficient of friction reached its lowest value of 0.11 , which is about $30 \%$ lower than with the base oil alone. On the other hand, even the smallest addition of hexadecanoic acid at a concentration of just $2 \mathrm{mmol} / \mathrm{l}$ decreased the COF by $30 \%$, to a value of about 0.1 . Increasing the concentration from 2 to $20 \mathrm{mmol} / \mathrm{l}$ had only a little effect on the COF; however, a monotonous decrease of the COF with higher concentrations was observed. At $20 \mathrm{mmol} / \mathrm{l}$ the COF for steel reached its lowest value of 0.094 .

A similar trend as with the coefficient of friction was observed in the wear behavior for the steel contact, Fig. 5b. The ball-wear volume for the base oil alone was $4.6 \times 10^{-4} \mathrm{~mm}^{3}$, Fig. $5 \mathrm{~b}$. When the alcohol was added at $2 \mathrm{mmol} / \mathrm{l}$, the average wear volume did not decrease; it even increased to $5.1 \times 10^{-4} \mathrm{~mm}^{3}$. When higher concentrations of alcohol were used, however, the wear began to decrease, reaching the lowest value of around $1.0 \times 10^{-4} \mathrm{~mm}^{3}$ at the highest two concentrations. This is about $80 \%$ lower than with the base oil alone. The results show that hexadecanol in higher concentrations decreased the coefficient of friction and wear (Fig. 5), while it increased the surface coverage of the steel surfaces (see Fig. 4). On the other hand, the addition of hexadecanoic acid at a concentration of just $2 \mathrm{mmol} / \mathrm{l}$ decreased the wear by $93 \%$, to a value of $3.34 \times 10^{5} \mathrm{~mm}^{3}$. Increasing the concentration from 2 to $20 \mathrm{mmol} / \mathrm{l}$ had relatively little effect on the wear; however, a continuous decrease in the wear for higher fatty acid concentrations was observed. At $20 \mathrm{mmol} / \mathrm{l}$ the wear of the steel ball was only $1.70 \times 10^{-5} \mathrm{~mm}^{3}$. The results show that the presence of fatty acid, even in a concentration as low as $2 \mathrm{mmol} / \mathrm{l}$, can drastically reduce the friction and wear. The fatty acid also resulted in a lower coefficient of friction and wear of the steel contacts than with the alcohol. This result correlates very well with the data obtained with the AFM (Fig. 4), where the fatty acid led to much better adsorption properties for the steel than the alcohol.

Fig. 6 shows the coefficient of friction (COF) and the ball wear for the DLC/DLC contact at an environmental temperature of $25{ }^{\circ} \mathrm{C}$. Notice the different scales of the wear for the DLC (Fig. 6b) and the steel (Fig. 5b). The coefficient of friction for the DLC contact (Fig. 6a) using base oil alone was around 0.059 , which is approximately $60 \%$ lower compared to the steel (Fig. 5a). The addition of hexadecanol or hexadecanoic acid did not affect the coefficient of friction of the DLC significantly. The measured values of the coefficient of friction varied between 0.056 and 0.060 for all the concentrations; the additive being either alcohol or fatty acid.

Although there were no significant changes in the coefficient of friction for the DLC, a decrease in the wear is clearly visible when either the alcohol or fatty acid was added to the base oil, Fig. 6 . The ball-wear volume was approximately $1.5 \times 10^{-5} \mathrm{~mm}^{3}$ when only the base oil was used, Fig. 6b. When the alcohol was added in the smallest concentration of $2 \mathrm{mmol} / \mathrm{l}$ the wear did not change much; however, at $5 \mathrm{mmol} / \mathrm{l}$ of alcohol the wear volume decreased to a value of $1.30 \times 10^{5} \mathrm{~mm}^{3}$. A further increase in the concentrations monotonously decreased the wear volume to a value of $1.27 \times 10^{-5} \mathrm{~mm}^{3}$ at the highest 
concentration. This is about $15 \%$ lower wear than with the base oil alone. On the other hand, the addition of hexadecanoic acid at concentrations of $2 \mathrm{mmol} / \mathrm{l}$ and $5 \mathrm{mmol} / \mathrm{l}$ decreased the wear by 13 to $17 \%$, to values of $1.30 \times 10^{5} \mathrm{~mm}^{3}$ and $1.23 \times 10^{5} \mathrm{~mm}^{3}$, respectively. Increasing the concentration above $5 \mathrm{mmol} / \mathrm{l} \mathrm{did}$ not influence the wear to any great extent, as it remained relatively constant, ranging from $1.23 \times 10^{5} \mathrm{~mm}^{3}$ to $1.28 \times 10^{5} \mathrm{~mm}^{3}$. Like with the steel contact, the fatty acid resulted in lower wear than the alcohol, especially at the lowest concentrations tested. This result correlates well with the AFM results (Fig. 4), where the fatty acid proved to have a better adsorption ability with respect to the DLC compared to the alcohol. Although the drop in wear is less obvious for the DLC than for the steel, it is important to consider the up to 30-times lower wear in the case of the DLC (Fig. 6b) compared to the steel (Fig. 5b), which makes any further reductions in the wear much more evident.

\section{DISCUSSION}

\subsection{AFM}

An AFM analysis of the adsorption of hexadecanol and hexadecanoic acid on the DLC surfaces was performed, using steel surfaces as a reference. After the solutions of various concentrations had been left on the surfaces to react, the samples were cleaned, which was an important part of the work. Cleaning with an ethanol sonication tended to remove the non-bonded and weakly bonded molecules. Only the strongly bonded molecules remained on the surface, which is discussed in detail later on. In spite of this relatively severe cleaning, a clear correlation between the surface coverage and the molecule concentration could be observed. The obtained results therefore imply that the AFM can be used to analyze the adsorption ability of polar molecules on various surfaces.

The monotonous increase of the surface coverage with an increasing concentration of the polar molecules at room temperature (Fig. 4a) could be explained by the theory that a larger number of active molecules present in the carrier fluid means that more binding sites on the surface can become occupied, which consequently manifests itself in an increased surface coverage. However, this holds only for low concentrations or a large number of available binding sites. Higher concentrations and/or a limited availability of free binding sites would result in the saturation of adsorption. Therefore, the surface coverage would level off at higher concentrations.
The heterogeneity of the affinity of the adsorption sites and the low adsorption ability of the molecules might well be the reason for the leveling off of the surface-coverage curves. In the case of hexadecanol and steel (Fig. 4a), the low surface coverage and the leveling off above the concentration of $15 \mathrm{mmol} / \mathrm{l}$ indicate the weak adsorption ability of the long-chain alcohol molecules with respect to the steel in static conditions. However, the same alcohol molecules seem to have a slightly better adsorption ability when in combination with the DLC surfaces. Since DLC coatings are known to be rather nonreactive towards surrounding species under static conditions [4] this result was surprising. On the other hand, the fatty acids resulted in a higher surface coverage of the steel than the DLC, which proves the well-known good adsorption ability of the fatty acid with respect to steel surfaces. Moreover, the fact that the fatty acid resulted in a higher surface coverage on both surfaces compared to the alcohol proves the overall, much better adsorption ability of the fatty acids compared to the alcohol. This very much agrees with several complementary studies, see [19] and [20].

Although the 100Cr6 steel and the a-C:H coating possess relatively similar total surface energies, the polar component of the surface energy of the steel is much larger, i.e., almost double, compared to the polar component of the a-C:H, which indicates the better overall adsorption ability of steel with respect to the polar molecules compared to the hydrogenated DLC [21]. This agrees well with the results of this study, where the surface coverage of the steel with fatty acid molecules was much greater compared to the DLC. In the case of hexadecanol, however, the differences in adsorption between the steel and the DLC are not so obvious, which may be due to the lower polarity of the alcohol compared to the fatty acid. Namely, the polarity of the alcohols may be too low to reliably differentiate the behavior based on the surface-energy theorem.

At $80{ }^{\circ} \mathrm{C}$ the relations between the surface coverage for both the additives and the surfaces remained the same, which proves that the above statements also hold true at elevated temperatures. However, by elevating the temperature the surface coverage increased drastically for the lowest concentrations in all cases, Fig. 4. This could be due to the better mobility of the molecules at higher temperatures, and as a result, more molecules hit the surface and adsorb. The affinity of the binding sites may change as well. The leveling off in the case of the hexadecanoic acid, where the surface coverage reached its highest values, may be caused by a limited 
and relatively small number of available adsorption sites on the surface. The slowly decreasing trend of the surface coverage on both surfaces in the case the hexadecanoic acid, above the concentration of $5 \mathrm{mmol} / \mathrm{l}$, might be a consequence of the micelle structures that can be formed from polar acid molecules at higher concentrations.

\subsection{Tribotests}

Tribological tests were performed to compare the friction and wear behaviors with the AFM results, and to investigate the molecules' ability to retain on the surface and to act as a potential boundary-lubricating agent. Although a minimum concentration (2 to 5 $\mathrm{mmol} / \mathrm{l}$ ) of alcohol molecules was necessary to achieve significant reductions in the friction and wear, their further decreasing with an increasing concentration is in agreement with the well-known fact that alcohols help to decrease the friction and wear of steel contacts [22] to [24]. Namely, higher concentrations enable a more complete adsorbed film, which protects the surface asperities from direct mechanical contact, passivates the worn and freshly exposed surfaces and therefore prevents any strong adhesion. Decreasing the COF and wear with the increasing hexadecanol concentration, therefore, combines well with the AFM results, Figs. 4.

In contrast to the hexadecanol, the hexadecanoic acid in a concentration as low as $2 \mathrm{mmol} / \mathrm{l}$ was sufficient to form an efficient protective film on the surface. Nevertheless, it was already proven that fatty acids readily form adsorbed layers and help to improve the tribological properties of metals, see [18] and [25] to [27]. However, the dependence of the tribological performance on the acid (or alcohol) concentration at $25{ }^{\circ} \mathrm{C}$ does not directly resemble the surface coverage measured with the AFM at $25^{\circ} \mathrm{C}$ (Fig. 4a). The reason for this is the increased contact temperature and wear. The temperature in the tribocontacts may rise well above the surrounding temperature due to the frictional heat [28]. The increased contact temperature, if not too high, usually enhances the adsorption. This is why the tribological behavior of steel (Fig. 5) correlates much better with the AFM results obtained at increased temperature (Fig. 4b) than at room temperature, Fig. 4a. In addition to the frictional heat, the wear causes the removal of the passivating surface layers, which creates new dangling bonds on the surface. This is an important phenomenon, in addition to temperature, that distinguishes the tribocontact from the static conditions.
The fact that the coefficient of friction of the DLC/DLC contact was not affected by the presence of the hexadecanol or hexadecanoic acid molecules (Fig. 6a) does not necessarily imply the absence of adsorption. It has been shown [5] that hydrogenated DLC surfaces, like in our case, possess inherently lowfriction properties due to the passivation of the surface dangling bonds by the hydrogen from the coating, which prevents the formation of strong adhesion bonds between the opposing surfaces. Passivating the surfaces with the polar molecules may therefore have no noticeable influence on the friction behavior of the coating, since the shear between the adsorbed hydrocarbon topcoats does not differ from the shear between the bare hydrogenated DLCs. This seems to be true at $25^{\circ} \mathrm{C}$ as well as at $80^{\circ} \mathrm{C}$.

In contrast to the friction, the wear of the DLC decreased in the presence of the hexadecanol and hexadecanoic acid molecules (Fig. 6b). Similar results, where the wear decreased in the presence of alcohol, i.e., pentanol, were also reported in another study with steel/DLC contacts [29]. According to the obtained results, we presume that a film of adsorbed polar molecules acts as a thin, highly viscous layer, which prevents direct mechanical contacts between the surface asperities and thus reduces the wear.

The fact that the acid always resulted in lower wear of the DLC compared to the alcohol, irrespective of the concentration used, again proves the superior adsorption capabilities of the acid compared to the alcohol. Moreover, trends in the wear reduction on DLC in the presence of the alcohol and acid seem to be similar as on the steel. Namely, the acid resulted in the greatest reduction of wear at the lowest concentration and caused only slight changes at higher concentrations. The alcohol, on the other hand, caused no noticeable changes at $2 \mathrm{mmol} / \mathrm{l}$, but it resulted in a monotonous decrease in the wear above $2 \mathrm{mmol} / \mathrm{l}$. These trends appear similar to those of the steel, despite the overall lower effect that both molecules had on the DLC compared to the steel. However, a much lower degree of wear of the DLC compared to the steel, which makes any further improvements in the case of the DLC very difficult, has to be considered here.

Nevertheless, the wear behavior of the DLC in the presence of the polar molecules also correlates well with the AFM data. This is especially true for the surface coverage obtained at $80{ }^{\circ} \mathrm{C}$ (Fig. 4b), which is due to the same reasons described earlier in the text for the steel. Besides wear, rubbing may also trigger a tribo-emission, which can occur at the surfaces of DLC, see [30] and [31]. Tribo-emitted electrons, ions 
and photons can ionize molecules, allowing them to chemisorb or even decompose, see [32] and [33]. The emission of charged particles, on the other hand, leaves charged areas on the surface, which then serve as new bonding sites. The wear and tribo-emission can thus affect the adsorption of polar molecules and befog the effect of the environmental temperature on adsorption. Accordingly, the tribocontact appears to enhance the chemisorption, which appears to be a preferable mechanism in the tribological tests. On the other hand, in the static AFM conditions, where the formation of dangling bonds is less probable and limited to higher temperatures, hydrogen bonding seems to be a more plausible mechanism for the molecule adsorption.

\subsection{On the Adsorption Mechanisms}

\subsubsection{Static Conditions}

Similar to steel, amorphous carbon coatings that are exposed to ambient air and moisture also possess a certain amount of oxides and hydroxides on the surface, see [34] and [35]. The amorphous structure and oxidation cause these surfaces to be heterogeneous in the sense that they contain exposed adsorption sites with a range of affinities for interactions with polar end-groups [36]. The surfaces of the amorphous carbon substrates therefore contain $\mathrm{sp}^{2}$ and $\mathrm{sp}^{3}$ bonded carbon atoms, whereas the surface bonds are passivated by hydrogen, oxides and hydroxides. Fig. 7 shows schematic diagrams illustrating several tentative adsorption mechanisms for alcohols and fatty acids in different environmental and contact conditions. In the
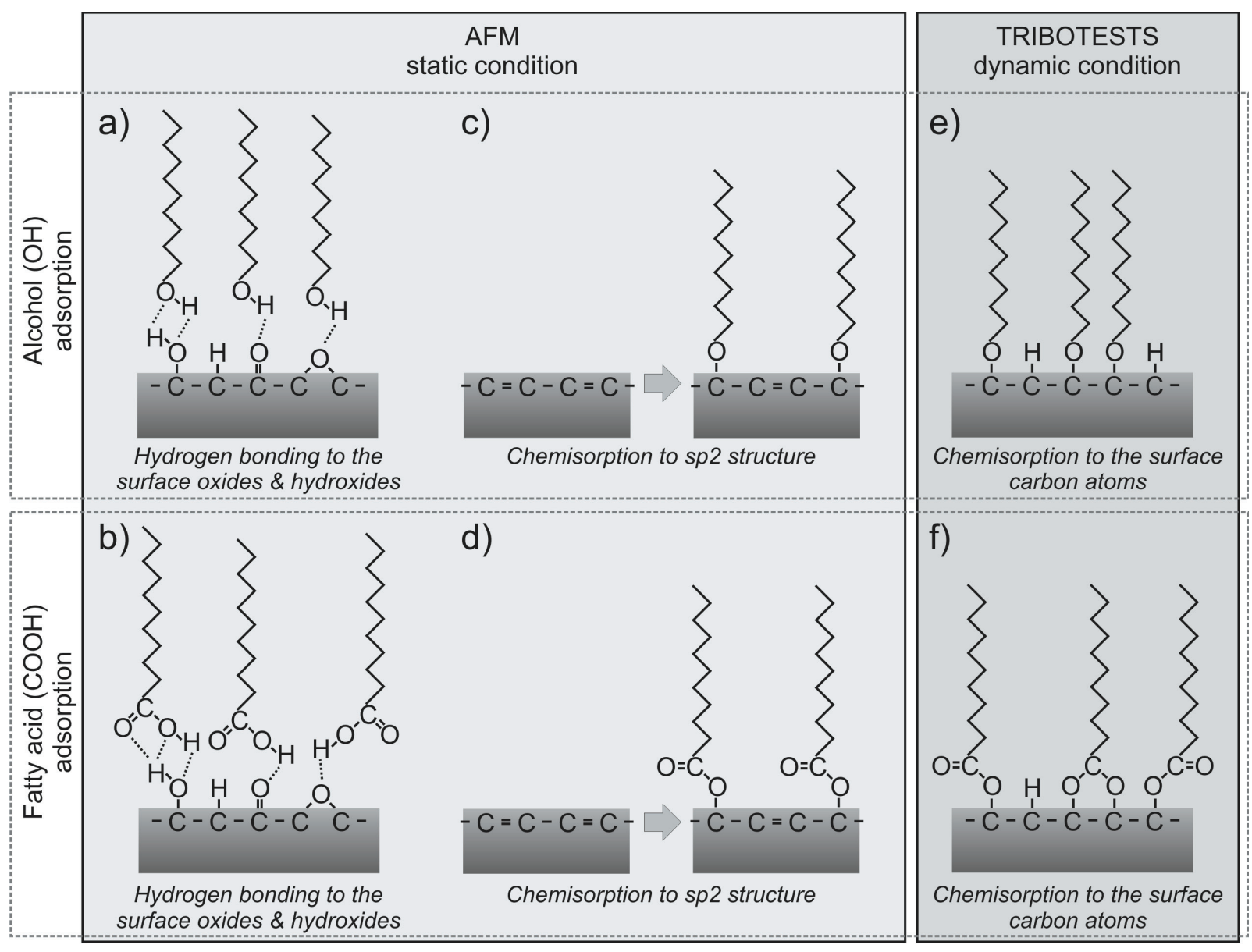

Fig. 7. Tentative adsorption mechanisms for alcohol and fatty acid molecules onto DLC; alcohol a) and fatty acid b) molecules physisorb by the hydrogen bonding to the surface oxides and hydroxides; in the static conditions the alcohol c) and fatty acid d) molecules may chemisorb to an unsaturated sp2 system; during the dynamic tribocontact conditions chemisorption of the alcohols e) and fatty acids f) to the surface carbon atoms is greatly enhanced 
static conditions, the alcohol or fatty acid molecules close to the surface physically adsorb by hydrogen bonding to surface oxides and hydroxides, Figs. 7a and $7 \mathrm{~b}$. Since the physical bonding is relatively weak $(\sim 20 \mathrm{~kJ} / \mathrm{mol})$ it be can easily disrupted by the ambient thermal energy or removed by solvent rinsing [35]. As proposed by Kasai [35] and [37], alcohol molecules can also chemisorb to the carbon surface, where chemical bonding occurs when the hydrogen atom from the hydroxyl endgroup migrates to the dangling bond inside the amorphous carbon structure, while the remaining alkoxy group interacts with the unsaturated system at the surface, Figs 7c. We assume that the fatty acids can chemisorb in a similar way, Fig 7d.

According to Kasai [35] and [37], such an adsorption process is slow at room temperature, but it can be accelerated by elevating the temperature. This agrees well with our results, where the adsorption of both alcohol and fatty acid molecules, the alcohol and acid, on DLC was greatly promoted at all concentrations when the temperature was increased from 25 to $80{ }^{\circ} \mathrm{C}$. Even though ultrasonic cleaning may cause the removal of a large fraction of physisorbed molecules, some of them may still persist on the surface and contribute to the total surface coverage. Their exact share of the total surface coverage, however, cannot be determined from the technique used in this work.

\subsubsection{Dynamic Conditions}

The rubbing during a tribological contact of DLC surfaces causes the removal of the surface oxides, hydroxides and even carbon atoms, which results in the wear of the material. The consequential absence of the surface passivating layers creates new dangling bonds on the freshly exposed carbon atoms. These dangling bonds tend to passivate themselves by reacting immediately with the surrounding species, like free hydrogen, oxygen and, to some extent, also polar alcohol or fatty acid molecules. The alcohol and fatty acid molecules chemisorb to the exposed dangling bonds by the attachment of the oxygen from the hydroxyl/carboxyl group onto the exposed surface carbon atoms. The hydrogen that gets cut off from the hydroxyl/carboxyl group during the chemisorption can passivate the remaining dangling bonds on the surface or gets removed from the contact as a $\mathrm{H}_{2}$ molecule. The alkyl chain of the alcohol therefore attaches to the surface by creating an ether bond (C-O-C), while the fatty acid presumably forms ester bonds. The ions, electrons and photons may be generated in the tribological contacts of the hydrogenated DLCs
[30] to [32], causing the formation of a triboplasma and tribocharging. A triboplasma at the DLC surface can cause tribochemical reactions, similar to those proposed for steel by Kajdas in the NIRAM approach [38].

All these phenomena contribute greatly to the chemisorption of the alcohol and fatty acid molecules on the DLC surfaces in the contact, Figs. $7 \mathrm{e}$ and $7 \mathrm{f}$. Since the physisorption is easily disrupted due to the relatively weak van der Waals forces, it can only have a minor effect on the friction and wear. The physisorbed molecules are presumably unable to sustain these boundary-lubrication conditions and such tribological improvements would not be observed. We therefore assume that it is the chemisorption that causes the significant improvements in the triboperformance, although both physisorption and chemisorption may be present in the contact.

The adsorption mechanisms for the hydrogenated DLC are in a way similar to the mechanisms of adsorption onto steel. However, the bonding energies between the polar molecules and the steel (iron-alkoxide/carboxylate bond) are presumably very different from the energies between the polar molecules and the DLC (ether/ester-type bond). Therefore, the ability of the additive molecules to adsorb on the DLC surface and thus affect the friction and wear may differ from the ability of the alcohol molecules adsorbed onto steel.

\section{CONCLUSIONS}

In this work we showed that AFM can be used successfully to detect islands of adsorbed molecules on steel and DLC. We showed that polar molecules can adsorb on the DLC also under static conditions, although the DLC is assumed to be rather nonreactive. The analysis of the surface coverage revealed that fatty acid possesses an overall superior adsorption ability compared to the related alcohol molecules. Comparing the results for the steel and the DLC revealed that fatty acid adsorbs better on the steel than on the DLC, while the opposite holds for the alcohol molecules. The presence of the fatty acid or alcohol molecules in the lubricant can also reduce the wear of the DLC coatings, which proves the adsorption ability of these molecules. The adsorbed alcohol and fatty acid molecules protected the surface asperities from direct mechanical contacts and thus helped to reduce the wear. At low concentrations (2 to 5 $\mathrm{mmol} / \mathrm{l}$ ) fatty acid resulted in lower wear compared to the alcohol, which proved the better adsorption ability of the acid. Above $7 \mathrm{mmol} / \mathrm{l}$ both molecules 
resulted in similar reductions in the wear, which - in contrast to the differences in the static AFM tests - is a consequence of the better film formation due to the enhanced adsorption on the tribo-activated surfaces. The fact that the adsorption of molecules had no significant influence on the coefficient of friction can be explained by the inherent low-friction properties of the hydrogenated DLC itself. To sum up, the results of this work showed that long-chain alcohols and fatty acids adsorb onto DLC and can therefore serve as potential green boundary-lubrication agents for DLC.

\section{ACKNOWLEDGMENTS}

The authors greatly appreciate the generous support of the Taiho Kogyo Tribology Research Foundation, Japan, as well as of F. Meunier from Sulzer Sorevi for providing the coatings. The authors also wish to thank J. Jelenc (Nanotul, Slovenia), whose help with the AFM analyses contributed greatly to this research.

\section{REFERENCES}

[1] Robertson, J. (2002). Diamond-like amorphous carbon. Materials Science and Engineering: R: Reports, vol. 37, no. 4-6, p. 129-281, DOI:10.1016/S0927796X(02)00005-0.

[2] Erdemir, A. (2004). Diamond-like carbon films. Tribology of Mechanical Systems, ASME Press, New York, p. 139-156, DOI:10.1115/1.802094.ch8.

[3] Neville, A., Morina, A., Haque, T., Voong, M. (2007). Compatibility between tribological surfaces and lubricant additives-How friction and wear reduction can be controlled by surface/lube synergies. Tribology International, vol. 40, no. 10-12, p. 1680-1695, DOI:10.1016/j.triboint.2007.01.019.

[4] Erdemir, A., Donnet, C. (2006). Tribology of diamondlike carbon films: recent progress and future prospects. Journal of Physics D: Applied Physics, vol. 39, R311-R327, DOI:10.1088/0022-3727/39/18/R01.

[5] Fontaine, J., Donnet, C., Grill, A., LeMogne, T. (2001). Tribochemistry between hydrogen and diamondlike carbon films. Surface and Coatings Technology, vol. 146-147, p. 286-291, DOI:10.1016/S02578972(01)01398-6.

[6] Erdemir, A. (2001). The role of hydrogen in tribological properties of diamond-like carbon films. Surface and Coatings Technology, vol. 146-147, p. 292-297, DOI:10.1016/S0257-8972(01)01417-7.

[7] Li, H., Xu, T., Wang, C., Chen, J., Zhou, H., Liu, H. (2007). Tribochemical effects on the friction and wear behaviors of a-C:H and a-C films in different environment. Tribology International, vol. 40, no. 1, p. 132-138, DOI:10.1016/j.triboint.2006.03.007.

[8] Wu, X., Ohana, T., Tanaka, A., Kubo, T., Nanao, H., Minami, I., Mori, S. (2008). Tribochemical investigation of DLC coating in water using stable isotopic tracers. Applied Surface Science, vol. 254, no. 11, p. 3397-3402, DOI:10.1016/j.apsusc.2007.11.024.

[9] Kano, M., Yasuda, Y., Okamoto, Y., Mabuchi, Y., Hamada, T., Ueno, T., Ye, J., Konishi, S., Takeshima, S., Martin, J.M., de Barros Bouchet, M.I., Le Mogne, T. (2005). Ultralow friction of DLC in presence of glycerol mono-oleate (GMO). Tribology Letters, vol. 18 , no. 2, p. 245-251, DOI:10.1007/s11249-004-27494.

[10] Matta, C., Joly-Pottuz, L., de Barros Bouchet, M.I., Martin, J.M., Kano, M., Zhang, Q., Goddard III, W.A. (2008). Superlubricity and tribochemistry of polyhydric alcohols. Physical Review B, vol 78, no. 8, p. 085436-1 - 085436-8, DOI:10.1103/PhysRevB.78.085436.

[11] de Barros Bouchet, M.I., Martin, J.M., Le-Mogne, T., Vacher, B. (2005). Boundary lubrication mechanisms of carbon coatings by MoDTC and ZDDP additives. Tribology International, vol. 38, no. 3, p. 257-264, DOI:10.1016/j.triboint.2004.08.009.

[12] Equey, S., Roos, S., Mueller, S., Hauert, R., Spencer, N.D., Crockett, R. (2008). Tribofilm formation from ZnDTP on diamond-like carbon. Wear, vol. 264, no. 3-4, p. 316-321, DOI:10.1016/j.wear.2007.03.012.

[13] Topolovec-Miklozic, K., Lockwood, F., Spikes, H. (2008). Behaviour of boundary lubricating additives on DLC coatings. Wear, vol. 256, no. 11-12, p. 1893-1901, DOI:10.1016/j.wear.2008.04.051.

[14] Kalin, M., Roman, E., Vižintin, J. (2007). The effect of temperature on the tribological mechanisms and reactivity of hydrogenated, amorphous diamondlike carbon coatings under oil-lubricated conditions. Thin Solid Films, vol. 515, no. 7, p. 3644-3652, DOI:10.1016/j.tsf.2006.09.049.

[15] Velkavrh, I., Kalin, M., Vižintin, J. (2009). The influence of viscosity on the friction in lubricated DLC contacts at various sliding velocities. Tribology International, vol. 42, no. 11-12, p. 1752-1757, DOI:10.1016/j.triboint.2009.04.022.

[16] Velkavrh, I., Kalin, M. (2012). Comparison of the effects of the lubricant-molecule chain length and the viscosity on the friction and wear of diamond-likecarbon coatings and steel. Tribology International, vol. 50, p. 57-65, DOI:10.1016/j.triboint.2012.01.008.

[17] Kalin, M., Vižintin, J., Vercammen, K., Barriga, J., Arnšek, A. (2006). The lubrication of DLC coatings with mineral and biodegradable oils having different polar and saturation characteristics. Surface and Coatings Technology, vol. 200, no. 14-15, p. 45154522, DOI:10.1016/j.surfcoat.2005.03.016.

[18] Lundgren, S. M., Persson, K., Mueller, G., Kronberg, B., Clarke, J., Chtaib, M., Claesson, P.M. (2007). Unsaturated Fatty Acids in Alkane Solution: Adsorption to Steel Surfaces. Langmuir, vol. 23, no. 21, p. 1059810602, DOI:10.1021/la700909v.

[19] Kalin, M., Simič, R., Hirayama, T., Geue, T., Korelis, P. (2014). Neutron-reflectometry study of alcohol adsorption on various DLC coatings. Applied Surface 
Science, vol. 288, p. 405-410, DOI:10.1016/j. apsusc.2013.10.047.

[20] Simič, R., Kalin, M., Hirayama, T., Korelis, P., Geue, T. (2013). Fatty acid adsorption on several DLC coatings studied by neutron reflectometry. Tribology Letters, (in Press), DOI:10.1007/s11249-013-0257-0.

[21] Kalin, M., Polajnar, M. (2013). The correlation between the surface energy, the contact angle and the spreading parameter, and their relevance for the wetting behaviour of DLC with lubricating oils. Tribology International, vol. 66, p. 225-233, DOI:10.1016/j. triboint.2013.05.007.

[22] Hardy, W., Doubleday, I. (1922). Boundary lubrication. The paraffin series. Proceedings of the Royal Society of London A, vol. 100, p. 550-574, DOI:10.1098/ rspa.1922.0017.

[23] Hu, Y., Liu, W. (1998). Tribological properties of alcohols as lubricating additives for aluminum-onsteel contact. Wear, vol. 218, no. 2, p. 244-249, DOI: 10.1016/S0043-1648(98)00162-8.

[24] Przedlacki, M. Kajdas, C. (2006). Tribochemistry of fluorinated fluids hydroxyl groups on steel and aluminum surfaces. Tribology Transactions, vol. 49, no. 2, p. 202-214, DOI:10.1080/05698190500544676.

[25] Raman, A., Gawalt, E.S. (2007). Self-assembled monolayers of alkanoic acids on the native oxide surface of SS316L by solution deposition. Langmuir, vol. 23, no. 5, p. 2284-2288, DOI:10.1021/la063089g.

[26] Sahoo, R.R., Biswas, S.K. (2009). Frictional response of fatty acids on steel. Journal of Colloid and Interface Science, vol. 333, no. 2, p. 707-718, DOI:10.1016/j. jcis.2009.01.046.

[27] Bowden, F.P., Gregory, J.N., Tabor, D. (1945). Lubrication of metal surfaces by fatty acids. Nature, vol. 156, p. 97-101, DOI:10.1038/156097a0.

[28] Kalin, M. (2004), Influence of flash temperatures on the tribological behaviour in low-speed sliding: a review. Materials Science and Engineering: A, vol. 374, no. 1-2, p. 390-397, DOI:10.1016/j.msea.2004.03.031.

[29] Marino, M.J., Hsiao, E., Bradley, L.C., Eryilmaz, O.L., Erdemir, A., Kim, S.H. (2011). Is ultra-low friction needed to prevent wear of diamond-like carbon (DLC)? An alcohol vapor lubrication study for stainless steel/
DLC interface. Tribology Letters, vol. 42, p. 285-291, DOI:10.1007/s11249-011-9771-0.

[30] Nakayama, K. (2004). Triboemission of electrons, ions, and photons from diamond-like carbon films and generation of tribomicroplasma. Surface \& Coatings Technology, vol. 188-189, p. 599-604, DOI: 10.1016/j. surfcoat.2004.07.103.

[31] Matta, C., Eryilmaz, O.L., de Barros Bouchet, M.I., Erdemir, A., Martin, J.M., Nakayama, K. (2009). On the possible role of triboplasma in friction and wear of diamond-like carbon films in hydrogen-containing environments. Journal of Physics D: Applied Physics, vol. 42, no. 7, p. 075307, DOI:10.1088/00223727/42/7/075307.

[32] Nakayama, K., Martin, J.M. (2006). Tribochemical reactions at and in the vicinity of a sliding contact. Wear, vol. 261, no. 3-4, p. 235-240, DOI:10.1016/j. wear.2005.10.012.

[33] Kajdas, C. (2005). Importance of the triboemission process for tribochemical reaction. Tribology International, vol. 38, no. 3, p. 337-353, DOI:10.1016/j. triboint.2004.08.017.

[34] Yang, M., Marino, M.J., Bojan, V.J., Eryilmaz, O.L., Erdemir, A., Kim, S.H. (2011). Quantification of oxygenated species on a diamond-like carbon (DLC) surface. Applied Surface Science, vol. 257, no. 17, p. 7633-7638, DOI:10.1016/j.apsusc.2011.03.152.

[35] Kasai, P.H., Shimizu, T. (2012). Bonding of hard disk lubricants with $\mathrm{OH}$-bearing end groups. Tribology Letters, vol. 46, p. 43-47, DOI:10.1007/s11249-0129916-9.

[36] Shukla, N., Gellman, A.J., Gui, J. (2000). The interaction of $\mathrm{CF} 3 \mathrm{CH} 2 \mathrm{OH}$ and $(\mathrm{CF} 3 \mathrm{CF} 2) 2 \mathrm{O}$ with amorphous carbon films. Langmuir, vol. 16, p. 65626568, DOI:10.1021/la0004496.

[37] Kasai, P.H. (2002). Carbon overcoat: Structure and bonding of Z-DOL. Tribology Letters, vol. 13, no. 3, p. 155-166, DOI:10.1023/A:1020101007436.

[38] Kajdas, C. (1987). About an anionic-radical concept of the lubrication mechanism of alcohols. Wear, vol. 116, no. 2, p. 167-180, DOI:10.1016/0043-1648(87)902316. 